\title{
Does intra-operative cardiac output monitoring improve outcomes for patients undergoing elective colorectal surgery within an enhanced recovery programme?
}

\author{
Muhammad Imran Aslam, Harriet Smith, Chelise Currow, Nadia Akhtar, Julia Merchant, Richard Evans, \\ Ugochukwu Ihedioha, Peter Kang
}

Department of Colorectal Surgery, Northampton General Hospital, NHS Trust, Cliftonville, Northampton NN1 5BD, UK.

Correspondence to: Mr. Muhammad Imran Aslam, Department of Colorectal Surgery, Northampton General Hospital, NHS Trust, Cliftonville, Northampton NN1 5BD, UK. E-mail: mia7@le.ac.uk

\begin{abstract}
How to cite this article: Aslam MI, Smith H, Currow C, Akhtar N, Merchant J, Evans R, Ihedioha U, Kang P. Does intra-operative cardiac output monitoring improve outcomes for patients undergoing elective colorectal surgery within an enhanced recovery programme? Mini-invasive Surg 2018;2:10. http://dx.doi.org/10.20517/2574-1225.2017.42
\end{abstract}

Received: 12 Oct 2017 First Decision: 1 Feb 2018 Revised: 7 Apr 2018 Accepted: 18 Apr 2018 Published: 27 Apr 2018

Science Editor: Charles F. Bellows Copy Editor: Jun-Yao Li Production Editor: Huan-Liang Wu

\begin{abstract}
Aim: Intra-operative cardiac output (CO) monitoring became a standard of care in Northampton General Hospital, UK, at the end of 2013. This study aimed to assess the effectiveness of intra-operative CO monitoring with oesophageal Doppler or LiDCO for patients undergoing elective colorectal surgery for cancer within an enhanced recovery after surgery (ERAS).
\end{abstract}

Methods: Data was prospectively collected over a 5-year period (March 2010 - Feb 2015) for patients undergoing elective colorectal surgery in the practice of a single surgeon. The ERAS protocol was applied for all the patients. There were 69 patients who had intra-operative CO monitoring with oesophageal Doppler or LiDCO and 144 patients who had no intra-operative CO monitoring. Results were analysed for post-operative outcomes (morbidity, mortality, readmission within 30 days, total length of hospital stay and admission to a high level of care facility).

Results: There was no significant difference in 30-day morbidity and readmission rates between the two examined groups. Forty-six percent of patients in the intra-operative CO monitoring group were admitted to a low level of care facility (ward) in comparison to $24 \%$ of patients in the no intra-operative CO monitoring group $(P=0.01)$.

Conclusion: Using intra-operative CO monitoring singnificantly might reduce the need for admission to critical care. A larger cohort study is needed to further confirm these findings and account for any co-founders.

Keywords: Non-invasive cardiac output monitoring, enhanced recovery, colorectal surgery, outcomes, perioperative care

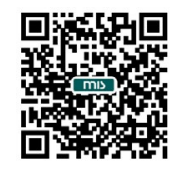




\section{INTRODUCTION}

Intra-operative cardiac output (CO) monitoring facilitates goal-directed intra operative fluid therapy (GDFT), a constituent of enhanced recovery pathways, which using a series of pre-, intra-and post-operative guidelines $^{[1]}$, has been shown to improve patient recovery after major surgery. These programmes have been shown to reduce the length of hospital stay, readmissions, and 30-day morbidity ${ }^{[2-8]}$.

Intra-operative fluid administration is important in preventing hypovolaemia and its complications including hypo-perfusion, impaired wound healing, anastomotic leak ${ }^{[9,10]}$ and a systemic inflammatory response $^{[2]}$, but there has been much debate in the literature about which intra-operative fluid (IOF) regimen is best for patients undergoing both open and laparoscopic colorectal surgery, with many advocating restrictive, more liberal or goal-directed fluid regimens with the aim of improving patient outcomes.

Restrictive regimens have been shown to be advantageous, reducing post-operative complications ${ }^{[11-15]}$, whereas liberal fluid administration has been associated with fluid overload and complications such as a reduction in gut motility, mucosal oedema and an increased risk of anastomotic breakdown ${ }^{[16,17]}$. It is also associated with pulmonary oedema and cardiac dysrhythmias ${ }^{[15,18-20]}$. GDFT aims to use dynamic measurements of cardiac output to guide IOF administration to maintain a "zero fluid balance" and thus reduce complications associated with inappropriate peri-operative fluid administration.

GDFT is achieved by monitoring cardiac output through various techniques, including the gold standard - pulmonary artery catheter-based thermodilution, but this is an invasive procedure associated with complications such as perforation of the pulmonary artery ${ }^{[21]}$. Vital sign measurements such as blood pressure and heart rate are not adequately specific or sensitive to guide fluid administration. Central venous pressure (CVP) monitoring has also been used, but this is limited in colorectal surgery where the patient is in the Trendelenburg position, creating a falsely elevated CVP by raising intrathoracic pressure, and has been shown to be an ineffective guide for IOF therapy ${ }^{[2]}$. Other techniques of continuous CO monitoring include oesophageal Doppler (CardioQ, Deltex Medical Ltd, Chichester, UK) and arterial pressure (AP) waveform analysis (LiDCO, LiDCO Ltd, Cambridge, UK) amongst others ${ }^{[23,24]}$.

Although there are many studies assessing the value of restrictive or liberal fluid regimens, further investigation into the role of GDFT and CO monitoring in intraoperative fluid administration and its role on patient outcomes is needed.

The aim of this study was to compare the surgical outcome measures between 2 groups of patients (those who received intra-operative CO monitoring using the oesophageal Doppler or LiDCO and those who had no intraoperative $\mathrm{CO}$ monitoring) who underwent elective colorectal surgery in an enhanced recovery programme.

\section{METHODS}

Data was prospectively collected over a 5-year period (March 2010 - Feb 2015) for patients undergoing elective colorectal surgery in a single surgeon's practice. Data collection and analysis were performed by two observers. Surgical outcome measures included 30- and 90-day mortality, morbidity, readmission, length of hospital stay (LOS) and admission to a high level care facility [intensive care unit (ICU) or high dependency unit (HDU)]. With the introduction of intra-operative cardiac output monitoring with either oesophageal Doppler or LiDCO as a standard of care in patients on the ERAS pathways at the end of 2013, we compared outcomes to those where no intra-operative cardiac output monitoring was used prior to this time. All the patients were cared for on the enhanced recovery after surgery (ERAS) pathways. Statistical analysis and inter-group comparisons were made using the Mann-Whitney $U$ test. A $P$-value of $<0.05$ was deemed statistically significant. 
Table 1. Patient characteristics for the intra-operative CO monitoring group (treatment group) and the no intra-operative CO monitoring group (control group)

\begin{tabular}{|c|c|c|c|}
\hline Characteristics & Treatment group & Control group & $\boldsymbol{P}$ \\
\hline Number & 69 & 144 & \\
\hline Age (years), median (range) & $68(22-87)$ & $70(37-93)$ & NS \\
\hline Gender, M:F & $37: 32$ & $74: 70$ & NS \\
\hline \multicolumn{4}{|l|}{ Mode of surgery, $n(\%)$} \\
\hline Routine & $59(85.5)$ & $124(86.1)$ & NS \\
\hline Emergency & $10(14.5)$ & $20(13.9)$ & \\
\hline \multicolumn{4}{|l|}{$\mathrm{ASA}, n(\%)$} \\
\hline I & $6(8.6)$ & $6(4.2)$ & NS \\
\hline$\|$ & $38(55)$ & $91(63.2)$ & \\
\hline III & $22(32)$ & $42(29.1)$ & \\
\hline IV & $1(1.5)$ & $4(2.8)$ & \\
\hline Unknown & $2(2.9)$ & $1(0.7)$ & \\
\hline \multicolumn{4}{|l|}{ Operation type, $n(\%)$} \\
\hline Right colonic surgery & $19(27.5)$ & $52(36)$ & NS \\
\hline Left colonic/rectal surgery & $50(72.5)$ & $92(64)$ & \\
\hline Cancer:benign & $57: 12(82.6: 17.4)$ & $133: 11(92.4: 7.6)$ & 0.05 \\
\hline Lap:Open:Conv & $48: 14: 7(69.5: 20.3: 10.2)$ & $82: 35: 27(57: 24: 19)$ & 0.05 \\
\hline Intra-operative systolic BP & $132(80-193)$ & $138(95-190)$ & NS \\
\hline Intra-operative heart rate & $77(56-109)$ & $74(56-110)$ & \\
\hline Operation time (min) & $168(48-365)$ & $158(45-380)$ & \\
\hline
\end{tabular}

NS: not significant $(P>0.05)$; M:F: male to female ratio; ASA: American Society of Anaesthesiologists; BP: blood pressure; Lap: laparoscopic; Conv: converted to open surgery

\section{RESULTS}

Two-hundred and thirty nine patients were reviewed (intra-operative CO monitoring, $n=69$ and no intraoperative CO monitoring, $n=144$ ). Post-operative outcomes were analysed. Most baseline characteristics were similar for both groups of patients [Table 1]. There was a statistically significant higher number of patients undergoing open surgery in the group with no intra-operative cardiac output monitoring $(P=0.05)$. There was also a statistically significant increase in the number of patients who had surgery for cancer in this group $(P=0.05)$. The greater number of patients in this group may explain this finding.

Only one patient died in this cohort within 30 days (in the no intra-operative CO monitoring group). There was no significant difference in the 30-day Clavien-Dindo morbidity (III-IV) for the two groups (5.7 vs. 5.5, $P=0.13)$. The median length of post-operative hospital stay for the treatment group was 6 days in comparison with 7 days for the control group. The difference in length of post-operative hospital stay between both groups was not statistically significant $(P=0.059)$. There was no statistically significant difference in 30-day readmission rate for both groups $(10.1 \%$ vs. $5.5 \%)(P=0.064)$.

A significantly higher proportion of patients (46.5\%) were admitted to level $2 / 3$ care facility for patients in the treatment group in comparison with patients in the control group $(24 \%, P=0.01)$ [Table 2]. Twenty-four percent of patients were admitted to high dependency unit (level 2 care) in the treatment group whereas 39\% of patients were admitted to level 2 care facility in control group. The median length of stay (2 days) in the high dependency unit (level 2 care) remained the same for both groups. No patients in the treatment group were admitted to the ICU. However, 11 patients (7.6\%) were admitted to ICU in the control group.

\section{DISCUSSION}

The study found that patients with intra-operative cardiac output monitoring and goal directed fluid therapy had a reduced number of admissions to levels 2 and 3 care compared with patients receiving no intra-operative CO monitoring or GDFT. HDU admissions were $24 \%$ in the treatment group and $39 \%$ in the control group. No patients were admitted to ICU in the treatment group whereas $7.6 \%$ of patients were 
Table 2. Comparisons of the post-operative outcomes for the intra-operative CO monitoring group (treatment group) and the no intra-operative $\mathrm{CO}$ monitoring group (control group)

\begin{tabular}{lccc}
\hline Post-operative outcomes & Treatment group & Control group & P \\
\hline 30-day mortality & 0 & 1 & NS \\
90-day mortality & 0 & 0 \\
30-day morbidity & 0 & $8(5.5)$ \\
Clavien-Dindo III-IV, $n$ (\%) & $4(5.7)$ & $8(5.5)$ \\
Readmission in 30days, $n$ (\%) & $7(10.1)$ & $7(2-112)$ \\
Length of hospital stay (days), median (range) & $6(2-92)$ & $56(39)$ \\
Length of stay in HDU & $17(24)$ & $2(1-13)$ \\
$\quad$ Patients, $n$ (\%) & $2(1-6)$ & & \\
Median (range) days & 0 & $11(7.6)$ \\
Length of stay in ICU & 0 & $2(1-15)$ \\
$\quad$ Patients, $n$ (\%) & & \\
Median (range) days & & \\
\hline
\end{tabular}

NS: not significant $(P>0.05)$; HDU: high dependency unit (level 2 - patients needing single organ support excluding mechanical ventilation such as renal hemofiltration or inotropes and invasive blood pressure monitoring. Staffed with one nurse to two patients); ICU: intensive care unit (level 3 - patient requiring two or more organ support or needing mechanical ventilation alone. Staffed with one nurse for per patient and usually with a doctor present in unit $24 \mathrm{~h}$ per day)

admitted to ICU in the control group. This could be due to several reasons: firstly, it may be that patients with intraoperative $\mathrm{CO}$ monitoring received optimised fluid therapy and subsequently required lower level of care, but the lack of data for the volumes of fluid administered to all patients leaves us unable to draw this conclusion. Secondly, CO monitoring provided the anaesthetists with up-to-date and accurate data about cardiovascular status and stability and may have influenced the need for postoperative care, hence, patients who were performing well having their care needs downgraded. Thirdly, adequate fluid administration intraoperatively would have reduced GI complications resulting from fluid overload or hypovolaemia. Fluid overload can lead to several harmful effects such as, generalised oedema, hindering tissue healing, detrimental effects on cardio-pulmonary functions, delayed recovery of gut functions ${ }^{[9]}$, decreased muscular oxygen tension ${ }^{[10]}$, increased risk of complications ${ }^{[11,12]}$ and is linked to poor survival rates $^{[13]}$. The effectiveness of intra-operative cardiovascular monitoring to reduce such complications has been proven in other published studies ${ }^{[25-30]}$. On the other hand, hypovolemia can lead to hypoperfusion, circulatory collapse, impaired wound healing, anastomotic leak ${ }^{[14,15]}$, bacterial translocations and endotoxaemia with activation of the systemic inflammatory respons ${ }^{[31]}$; all of which account for the need of prolonged stay in high level care facilities post-operatively. Noblett et al. ${ }^{[2]}$ have shown a reduction in peak systemic inflammatory cytokine (IL-6) levels for patients undergoing CO monitoring with Doppler. This study concluded that the Doppler intervention reduced the systemic inflammatory response to surgical trauma, preserved splanchnic perfusion and thereby reduced gut-related inflammatory responses. Fourthly, results could also have been affected by the fact that, within the control group, more patients had open surgical procedures for malignancy, and many cases were converted to open $(n=27)$, thus those patients, subsequently, required more HDU/ICU admissions. Therefore, the availability of intra-operative CO data in that patient group would have influenced the decision for admission to HDU/ICU care is not known.

The median length of hospital stay for treatment group was shorter in comparison to control group (6 vs. 7 days). But, this difference did not reach statistical significance $(P=0.078)$. All patients in the treatment and control groups were cared for on the ERAS programme. Outcomes associated with ERAS are dependent on multiple peri-operative factors.

The limitations of this study are a lack of data about the accurate volume of intra-operative fluids administrated, intra-operative CO variations, P-POSSUM scores and the rationale of the decision for admission to different levels of post-operative care areas. Availability of such data would have allowed adjusting for these confounding factors to assess post-operative outcomes more accurately. This study lacks the data about study population representative for other surgeons, variability in ethnicity and socioeconomic 
status. More patients in the control period had open operations and more had conversions from laparoscopic to open procedures that during the $\mathrm{CO}$ measurement period. Patients in the earlier period may have required more advanced care because of the higher level of invasiveness of the operation. These differences alone would explain a large percentage of the change in level 2/3 care required in the earlier period, and not the implementation of CO monitoring. Due to the lack of data about the precise decision for admission in ICU/ HDU in the control group did not allow analysis for these co-founders. The authors did not notice a change in practice for the use of bowel preparation for colon surgery patients. No mechanical bowel preparation is used at the unit for right colonic surgery and only Phosphate enema is used for left sided colonic and rectal surgery. Enhanced recovery protocols have recommended the elimination of mechanical bowel preparation which would reduce IV volume support for patients undergoing colorectal surgery. Though practice for bowel preparation did not change in study period, a lack of data in the consistency in bowel preparation over the entire time of the study highlights the issue that even a minor change in practice combined with less invasive surgical procedures makes the postoperative care of the patients in the two periods of time very different.

Intra-operative indices of tissue hypo-perfusion resulting in gastrointestinal dysfunction are the most common post-operative complications in patients undergoing moderate-to high risk emergency GI surgery. Intra-operative $\mathrm{CO}$ optimisation and GDFT for patients undergoing colorectal surgery reduces the postoperative morbidity, mortality and length of hospital stay ${ }^{[9]}$. GDFT has also been shown to be cost effective in reducing hospital stays and the surgical complications ${ }^{[32,33]}$. It would be interesting to extend this study to use intra-operative cardiac output monitoring for patients undergoing emergency laparotomy and to assess the outcomes through the National Emergency Laparotomy Audit.

In conclusion, the use of intra-operative cardiac monitoring does not significantly alter the immediate postoperative outcomes; however, it reduces the need for admission to level $2 / 3$ care facilities post-operatively. Intra-operative cardiac output monitoring might become an effective way to reduce the need for higher level critical care beds in patients undergoing elective colorectal surgery. A larger cohort study is needed to further confirm these findings and account for any co-founders.

\section{DECLARATIONS}

\section{Authors' contributions}

Conception and design: Merchant J, Evans R, Ihedioha U, Kang P

Acquisition of data: Aslam MI, Smith H, Akhtar N

Analysis and interpretation of data: Aslam MI

Article drafting: Aslam MI, Smith H, Akhtar N

Revision for important intellectual content: Currow C, Merchant J, Evans R, Ihedioha U, Kang P

Final approval: Aslam MI, Smith H, Currow C, Akhtar N, Merchant J, Evans R, Ihedioha U, Kang P

\section{Financial support and sponsorship}

None.

\section{Conflicts of interest}

There are no conflicts of interest.

\section{Patient consent}

No personal information for patients involved in the article.

\section{Ethics approval}

Ethics review was not required by the institution for a retrospective analysis for prospectively maintained database. 


\section{Copyright}

(C) The Author(s) 2018.

\section{REFERENCES}

1. Khan S, Gatt M, Horgan A, Anderson I, MacFie J. Issues in Professional Practice. Guidelines for Implementation of Enhanced Recovery Protocols. London: Association of Surgeons of Great Britain and Ireland; 2009.

2. Noblett SE, Snowden CP, Shenton BK, Horgan AF. Randomised clinical trial assessing the effect of Doppler-optimised fluid management on outcome after elective colorectal resection. Br J Surg 2006; 93:1069-76.

3. Abbas SM, Hill AG. Systematic review of the literature for the use of oesophageal Doppler monitory for fluid replacement in major abdominal surgery. Anaesthesia 2008;63:44-51.

4. Gustafsson UO, Hausel J, Thorell A, Ljungqvist O, Soop M, Nygren J. Adherence to enhanced recovery after surgery protocol and outcomes after colorectal cancer surgery. Arch Surg 2011;146:571-7.

5. Hamilton MA, Cecconi M, Rhodes A. Systematic review and meta-analysis on use of preemptive haemodynamic intervention to improve postoperative outcomes in moderate and high risk surgical patients. Anaesth Analg 2011;112:1274-6.

6. Gan TJ, Soppitt A, Maroof M, El-Moalem H, Robertson KM, Moretti E, Dwane P, Glass PS. Goal-directed intra-operative fluid administration reduces length of hospital stay after major surgery. Anaesthesiology 2002;97:820-6.

7. Grocott MP, Mythen MG, Gan TJ. Peri-operative fluid management and clinical outcomes in adults. Anaesth Analg 2005;100:1093-106.

8. Venn R, Steele A, Richardson P, Poloniecki J, Grounds M, Newman P. Randomise controlled trial to investigate influence of the fluid challenge on duration of hospital stay and peri-operative mortality in patients with hip fractures. Br J Anaesth 2002;88:65-71.

9. Bennett-Guerrero E, Feierman DE, Barclay GR, Parides MK, Sheiner PA, Mythen MG, Levine DM, Parker TS, Carroll SF, White ML, Winfree WJ. Preoperative and intraoperative predictors of postoperative morbidity, poor graft function, and early rejection in 190 patients undergoing liver transplantation. Arch Surg 2001;136:1177-83.

10. Mythen MG, Webb AR. Intra-operative gut mucosal hypoperfusion is associated with increased post-operative complications and cost. Intensive Care Med 1994;20:99-104.

11. Lobo DN, Bostock KA, Neal KR, Perkins AC, Rowlands BJ, Allison SP. Effect of salt and water balance on recovery of gastrointestinal function after elective colonic resection: a randomised controlled trial. Lancet 2002;359:1812-8.

12. Branstrup B, Tønnesen H, Beier-Holgersen R, Hjortsø E, Ørding H, Lindorff-Larsen K, Rasmussen MS, Lanng C, Wallin L, Iversen LH, Gramkow CS, Okholm M, Blemmer T, Svendsen PE, Rottensten HH, Thage B, Riis J, Jeppesen IS, Teilum D, Christensen AM, Graungaard B, Pott F; Danish Study Group on Perioperative Fluid Therapy. Effects of intravenous fluid restriction on post operative complications: comparison of two perioperative fluid regimens: a randomised assessor-blinded multicentre trial. Ann Surg 2003;238:641-8.

13. Nisanevich V, Felsenstein I, Almogy G, Weissman C, Einav S, Matot I. Effect of intraoperative fluid management on outcome after intraabdominal surgery. Anaesthesiology 2005;103:25-32.

14. Abraham-Nordling M, Hjern F, Pollack J, Prytz M, Borg T, Kressner U. Randomised clinical trial of fluid restriction in colorectal surgery. Br J Surg 2012;99:186-91.

15. Holte K, Foss NB, Andersen J, Valentiner L, Lund C, Bie P, Kehlet H. Liberal or restrictive fluid administration in fast track colonic surgery: a randomised, double-blind study. Br J Anaesth 2007;99:500-8.

16. Holte K, Sharrock NE, Kehlet H. Pathophysiology and clinical implications of perioperative fluid excess. Br J Anaesth 2002;89:622-32.

17. Joshi GP. Intraoperative fluid restriction improves outcome after major elective gastrointestinal surgery. Anaesth Analg 2005;101:601-5.

18. Lang K, Boldt J, Suttner S, Haisch G. Colloids versus crystalloids and tissue oxygen tension in patients undergoing major abdominal surgery. Anesth Analg 2001;93:405-9.

19. Møller AM, Pedersen T, Svendsen PE, Engquist A. Perioperative risk factors in elective pneumonectomy: the impact of excess fluid balance. Eur J Anaesthesiol 2002;19:57-62.

20. Lowell JA, Schifferdecker C, Driscoll DF, Benotti PN, Bistrian BR. Postoperative fluid overload: not a benign problem. Crit Care Med 1990;18:728-33.

21. Bowdle TA. Complications of invasive monitoring. Anaesthesiol Clin North America 2002;20:571-88.

22. Futier E, Constantin JM, Petit A, Chanques G, Kwiatkowski F, Flamein R, Slim K, Sapin V, Jaber S, Bazin JE. Conservative vs restrictive individualised goal-directed fluid replacement strategy in major abdominal sugery: a prospective randomised trial. Arch Surg 2010;145:1193-220.

23. Marik PE, Cavallazzi R. Does the central venous pressure predict fluid responsiveness? An updated meta-analysis and a plea for some common sense. Crit Care Med 2013;41:1774-81.

24. Funk DJ, Moretti EW, Gan TJ. Minimally invasive cardiac output monitoring in the perioperative setting. Anaesth Analg 2009;108:887-97.

25. Vincent JL, Pelosi P, Pearse R, Payen D, Perel A, Hoeft A, Romagnoli S, Ranieri VM, Ichai C, Forget P, Della Rocca G, Rhodes A. Perioperative cardiovascular monitoring of high risk patients: a consensus of 12. Crit Care 2015;19:224.

26. Nordström J, Hällsjö-Sander C, Shore R, Björne H. Stroke volume optimisation in elective bowel surgery: a comparison between pulse power wave analysis (LiDCOrapid) and oesophageal doppler (CardioQ). Br J Anaesth 2013;110:374-80.

27. Mowatt G, Houston G, Hernandez R, De Verteuil R, Fraser C, Cuthbertson B, Vale L. Systematic review of the clinical effectiveness and cost effectiveness of oesophageal Doppler monitoring in critically ill and high risk surgical patients. Health Technol Assess 2009;13:iii-iv, ix-xii, 1-95.

28. Shoemaker WC, Wo CC, Thangathurai D, Velmahos G, Belzberg H, Asensio JA, Demetriades D. Hemodynamic patterns of survivors and nonsurvivors during high risk elective surgical operations. World J Surg 1999;23:1264-70.

29. Shaw AD, Weavind LM, Parmley CL. Comparison of thermodilution, esophageal Doppler and transoesophageal echocardiography data in 
the hemodynamic assessment of critically ill cancer patients. Crit Care Med 2000;28:A73.

30. Singer M, Bennett ED. Noninvasive optimization of left ventricular filling using oesophageal Doppler. Crit Care Med 1991;19:1132-7.

31. Jakob SM, Takala J. Splanchnic hemodynamics in critical illness. Curr Opin Crit Care 2000;6:123-9.

32. Manecke G, Asemota A, Michard F. Tackling the economic burden of potsurgical complications: would perioperative goal directed fluid therapy help? Crit Care 2014;18:566.

33. Legrand G, Ruscio L, Benhamou D, Pelletier-Fleury N. Goal-Directed fluid therapy guided by cardiac monitoring during high risk abdominal surgery in adult patients: cost effectiveness analysis of esophageal Doppler and arterial pulse pressure waveform analysis. Value Health 2015;18:605-13. 